\title{
Simplifying prediction of disease progression in pre-symptomatic type 1 diabetes using a single blood sample
}

\author{
Naiara G. Bediaga ${ }^{1,2}$ (D) C Connie S. N. Li-Wai-Suen ${ }^{2,3}$ (D) Michael J. Haller ${ }^{4} \cdot$ Stephen E. Gitelman $^{5}$ (D) \\ Carmella Evans-Molina ${ }^{6}$ (D) $\cdot$ Peter A. Gottlieb ${ }^{7} \cdot$ Markus Hippich $^{8}$ (D) $\cdot$ Anette-Gabriele Ziegler ${ }^{8,9}$ (D) $\cdot$ Ake Lernmark $^{10}$ (D) \\ Linda A. DiMeglio ${ }^{6,11}$ (D) - Diane K. Wherrett ${ }^{12}$ - Peter G. Colman ${ }^{13}$ (D) - Leonard C. Harrison ${ }^{1,2}$ (D) \\ John M. Wentworth ${ }^{1,2,13}$
}

Received: 1 December 2020 / Accepted: 7 April 2021 / Published online: 2 August 2021

(C) The Author(s) 2021

\begin{abstract}
Aims/hypothesis Accurate prediction of disease progression in individuals with pre-symptomatic type 1 diabetes has potential to prevent ketoacidosis and accelerate development of disease-modifying therapies. Current tools for predicting risk require multiple blood samples taken during an OGTT. Our aim was to develop and validate a simpler tool based on a single blood draw. Methods Models to predict disease progression using a single OGTT time point ( $0,30,60,90$ or 120 min) were developed using TrialNet data collected from relatives with type 1 diabetes and validated in independent populations at high genetic risk of type 1 diabetes (TrialNet, Diabetes Prevention Trial-Type 1, The Environmental Determinants of Diabetes in the Young [1]) and in a general population of Bavarian children who participated in Fr1da.

Results Cox proportional hazards models combining plasma glucose, C-peptide, sex, age, BMI, HbA 1 c and insulinoma antigen-2 autoantibody status predicted disease progression in all populations. In TrialNet, the AUC for receiver operating characteristic curves for models named $\mathrm{M}_{60}, \mathrm{M}_{90}$ and $\mathrm{M}_{120}$, based on sampling at 60, 90 and 120 min, was 0.760 , 0.761 and 0.745, respectively. These were not significantly different from the AUC of 0.760 for the gold standard Diabetes Prevention Trial Risk Score, which requires five OGTT blood samples. In TEDDY, where only 120 min blood sampling had been performed, the $\mathrm{M}_{120}$ AUC was 0.865 . In Fr1da, the $\mathrm{M}_{120}$ AUC of 0.742 was significantly greater than the $\mathrm{M}_{60}$ AUC of 0.615 .

Conclusions/interpretation Prediction models based on a single OGTT blood draw accurately predict disease progression from stage 1 or 2 to stage 3 type 1 diabetes. The operational simplicity of $\mathrm{M}_{120}$, its validity across different at-risk populations and the requirement for $120 \mathrm{~min}$ sampling to stage type 1 diabetes suggest $\mathrm{M}_{120}$ could be readily applied to decrease the cost and complexity of risk stratification.
\end{abstract}

Ake Lernmark

ake.lernmark@med.lu.se

John M. Wentworth wentworth@wehi.edu.au

1 Department of Population Health and Immunity, Walter and Eliza Hall Institute, Parkville, VIC, Australia

2 Department of Medical Biology, University of Melbourne, Parkville, VIC, Australia

3 Department of Bioinformatics, Walter and Eliza Hall Institute, Parkville, VIC, Australia

4 University of Florida Diabetes Institute, Gainesville, FL, USA

5 Department of Pediatrics and Diabetes Center, University of California at San Francisco, San Francisco, CA, USA

6 Center for Diabetes and Metabolic Diseases, Indiana University School of Medicine, Indianapolis, IN, USA
7 Barbara Davis Center, University of Colorado School of Medicine, Aurora, CO, USA

8 Helmholtz Zentrum München, Institute of Diabetes Research, German Research Center for Environmental Health, Munich-Neuherberg, Germany

9 Forschergruppe Diabetes, Technical University Munich at Klinikum rechts der Isar, Munich, Germany

10 Department of Clinical Sciences, Lund University/CRC, Skåne University Hospital, Malmö, Sweden

11 Division of Pediatric Endocrinology, Department of Pediatrics, Indiana University School of Medicine, Indianapolis, IN, USA

12 Division of Endocrinology, Department of Pediatrics, Hospital for Sick Children, University of Toronto, Toronto, ON, Canada

13 Department of Diabetes and Endocrinology, Royal Melbourne Hospital, Parkville, VIC, Australia 


\section{Research in context}

\section{What is already known about this subject?}

- Screening for pre-symptomatic type 1 diabetes is increasing

- Current tests to predict disease progression require multiple blood samples following oral glucose challenge, which is costly and logistically difficult

What is the key question?

- Can a simpler test, based on a single blood draw, be developed?

\section{What are the new findings?}

- A test called $M_{120}$, based on a blood sample collected $120 \mathrm{~min}$ after oral glucose challenge, has been developed

- $\mathrm{M}_{120}$ has comparable performance to the gold standard Diabetes Prevention Trial Risk Score in relatives who participated in TrialNet

- $M_{120}$ also performed well in the younger TEDDY population of genetically at-risk children and in the Fr1 da general population study

\section{How might this impact on clinical practice in the foreseeable future?}

- Risk stratification based on a single blood draw, already performed to stage type 1 diabetes, will be simpler and less costly to perform than current methods that require at least two blood draws during the oral glucose tolerance test

Keywords Disease progression · OGTT $\cdot$ Prediction $\cdot$ Prevention $\cdot$ Risk stratification $\cdot$ Type 1 diabetes

$\begin{array}{ll}\text { Abbreviations } \\ \text { AIC } & \text { Akaike's information criterion } \\ \text { DPT-1 } & \text { Diabetes Prevention Trial-Type 1 } \\ \text { DPTRS } & \text { Diabetes Prevention Trial Risk Score } \\ \text { GADA } & \text { GAD autoantibodies } \\ \text { IA-2A } & \text { Insulinoma antigen-2 autoantibodies } \\ \text { IAA } & \text { Insulin autoantibodies } \\ \text { ROC } & \text { Receiver operating characteristic } \\ \text { TEDDY } & \begin{array}{l}\text { The Environmental Determinants } \\ \text { of Diabetes in the Young }\end{array} \\ \text { ZnT8A } & \begin{array}{l}\text { Zinc transporter-8 autoantibodies } \\ \end{array}\end{array}$

\section{Introduction}

Interest in autoantibody screening for type 1 diabetes risk has increased following the demonstration that early diagnosis prevents ketoacidosis [1-3] and provides opportunities to delay disease progression with immune therapies [4, 5]. Type 1 diabetes screening programmes underway in Europe, North America, Australia and New Zealand test for autoantibodies against insulin (IAA), GAD (GADA), insulinoma antigen-2 (IA-2A) and zinc transporter-8 (ZnT8A) [6-8].
The presence of two or more autoantibodies confers a very high lifetime risk of disease progression to insulin dependence [9] and has prompted the reclassification of type 1 diabetes as an autoimmune beta cell disorder defined primarily by immune rather than metabolic markers $[10,11]$.

Type 1 diabetes is now diagnosed when two or more islet autoantibodies are detected. Three disease stages based on oral glucose tolerance and $\mathrm{HbA}_{1 \mathrm{c}}$ have been defined. Stage 1 is defined by normal glucose tolerance and $\mathrm{HbA}_{1 \mathrm{c}}$, and stage 2 by impaired glucose tolerance and $\mathrm{HbA}_{1 \mathrm{c}}$ from 39 to 46 $\mathrm{mmol} / \mathrm{mol}(5.7 \%$ to $6.4 \%)$, inclusive [11]. Both of these stages are asymptomatic. Stage 3 satisfies current diagnostic criteria for diabetes mellitus [12] and is usually accompanied by symptoms of hyperglycaemia. While this staging system is important for helping the medical and lay communities understand the progression of a largely silent autoimmune disease, staging is also used to determine eligibility for prevention trials. To differentiate between type 1 diabetes stages 1,2 and 3, autoantibody-positive individuals undergo OGTTs, in which glucose is measured at baseline and 120 min after the glucose load. OGTTs performed in a number of research studies have collected glucose values at the 30,60 and 90 min time points to further define risk characteristics [13]. However, these additional time points greatly increase the costs and complicate the logistics of the OGTT. In order to conserve 
limited resources and increase participation, some screening programmes are transitioning from a multiple-time-point OGTT to the standard clinical model in which sampling is performed only at baseline and $120 \mathrm{~min}$.

The rate of progression from early-stage ( 1 or 2 ) type 1 diabetes to stage 3 type 1 diabetes is highly relevant for affected individuals and a critical determinant of both the sample size and duration of prevention trials. Younger age of seroconversion and the presence of IA-2A are associated with an increased risk of disease progression and have been used to predict its rate [14, 15]. However, more accurate risk stratification is afforded by considering glucose and C-peptide excursions during the OGTT. Currently, three stratification tools for predicting disease progression in pre-symptomatic type 1 diabetes have been validated. The Diabetes Prevention Trial Risk Score (DPTRS) incorporates age, BMI, and glucose and C-peptide at five OGTT time points [16], whereas the simpler Index60 endpoint is based on fasting C-peptide and the glucose and C-peptide at the $60 \mathrm{~min}$ time point [17]. The recently reported DPTRS60 score combines age and BMI with the inputs used to calculate Index60 [18]. These tools were developed using first-degree relative data from the Diabetes Prevention Trial-Type 1 (DPT-1) that began over 25 years ago, and performed initial participant screening with older assays for islet autoantibodies and C-peptide. These models were trained using data from single- as well as multipleautoantibody-positive individuals, potentially limiting their applicability to the current staging paradigm that requires the presence of two or more autoantibodies [11]. In addition, the inputs used to develop DPTRS and Index60 were selected on the basis of univariate association with the outcome of type 1 diabetes, potentially missing interactions that contribute to disease risk.

Screening for type 1 diabetes autoantibodies, now extending into the general population [19], would benefit practically from the development of a broadly applicable and simple to administer tool to assess risk of disease progression from stage 1 or 2 to stage 3 type 1 diabetes, based on fewer OGTT time points. Our recent success in validating a model based on single-time-point measures to estimate beta cell function in stage 3 disease [20] led us to hypothesise that a simpler tool could be devised to assess risk of progression to stage 3 . In the present study, we used the large Type 1 Diabetes TrialNet dataset [6] to develop and validate models based on a single OGTT time point that accurately predicted progression from stage 1 or 2 to stage 3 type 1 diabetes in other at-risk populations.

\section{Methods}

Data collection Each protocol was approved by a human research ethics committee and was carried out in accordance with the Declaration of Helsinki as revised in 2008.

The TrialNet TN-01 Pathway to Prevention Study (NCT00097292) is an islet autoantibody screening and metabolic monitoring programme that has operated in North America, Europe, Australia and New Zealand since 2004. Individuals aged up to 45 years with a first-degree relative with type 1 diabetes and those aged up to 20 years with a first/ second/third-degree relative with type 1 diabetes are screened for IAA, GADA, IA-2A and ZnT8A. TN-01 data current to December 2019 were downloaded in January 2020 and erroneous outlier values removed. Eligibility required fasting glucose $<7.0 \mathrm{mmol} / \mathrm{l}(126 \mathrm{mg} / \mathrm{dl}), 120 \mathrm{~min}$ glucose $<11.1 \mathrm{mmol} / \mathrm{l}$ (200 $\mathrm{mg} / \mathrm{dl}), \mathrm{HbA}_{1 \mathrm{c}}<48 \mathrm{mmol} / \mathrm{mol}(6.5 \%)$, age at least 2 years and BMI between 12 and $40 \mathrm{~kg} / \mathrm{m}^{2}$. To enter the TrialNet multipleautoantibody training population, participants needed complete data for the input measures of interest (electronic supplementary material [ESM] Table 1) and had an OGTT either at the same time that they first tested positive to multiple autoantibodies or at their next study visit (median [Q1, Q3] time between screening and OGTT $1.8[0.3,3.0]$ months). The TrialNet multipleautoantibody validation population comprised individuals who met the same glucose, $\mathrm{HbA}_{1 \mathrm{c}}$, age and BMI criteria, and who had all measures required to calculate the DPTRS and the newer risk scores. These participants were not included in the training population because they underwent OGTT testing two or more visits after screening positive to multiple autoantibodies, lacked data for HLA genotype or did not have data for ZnT8A, which was only introduced into TrialNet in 2012. The median [Q1, Q3] time between screening and OGTT in the training population was $3.2[1.5,9.8]$ months. The TrialNet single-antibody population comprised 612 participants who tested positive to only one autoantibody and who underwent an OGTT that returned normal or impaired glucose tolerance and $\mathrm{HbA}_{1 \mathrm{c}}<48 \mathrm{mmol} / \mathrm{mol}(6.5 \%)$.

Data for the DPT-1 (NCT00004984) and The Environmental Determinants of Diabetes in the Young (TEDDY) study (NCT00279318) were obtained from the National Institute of Diabetes and Digestive and Kidney Diseases data repository in March and April 2020. DPT-1 recruited relatives with stage 1 or 2 type 1 diabetes between 1994 and 2003 and showed that neither parenteral nor oral insulin delayed progression to stage 3 [21, 22]. DPT-1 participants were positive for islet cell antibodies by indirect immunofluorescence assay and negative for the protective $H L A-D Q A 1 * 01: 02-D Q B 1 * 06: 02$ haplotype. Some assays for IAA were performed during the study whereas other IAA measurements, and all GADA and IA-2A measurements, were performed retrospectively on stored samples. TEDDY is a birth cohort study that enrolled 8668 North American and European newborns whose HLA genotype or family history conferred an increased risk of type 1 diabetes [23]. Data for multiple-autoantibody-positive children who had undergone a limited OGTT (blood sampling at $120 \mathrm{~min}$ ) were extracted. For both DPT-1 and TEDDY, participants who had $120 \mathrm{~min}$ glucose of $11.1 \mathrm{mmol} / \mathrm{l}(200 \mathrm{mg} / \mathrm{dl})$ or more, those who were missing data needed to calculate risk scores and those who had not been followed beyond their first OGTT were excluded. 
The Frlda study (NCT04039945) enrolled children aged 2 to 6 years from the general Bavarian population [7]. Children who screened positive for two or more islet autoantibodies were invited to undergo an OGTT with blood sampling at 0 , 30, 60, 90 and $120 \mathrm{~min}$. Participants with missing results for BMI, $\mathrm{HbA}_{1 \mathrm{c}}$ and IA-2A were excluded. Data were current to March 2020.

Stage 2 type 1 diabetes was defined as a fasting glucose of 5.6 to $7.0 \mathrm{mmol} / \mathrm{l}(100$ to $125 \mathrm{mg} / \mathrm{dl})$, a glucose at $30-90 \mathrm{~min}$ greater than $11.1 \mathrm{~mol} / \mathrm{l}(200 \mathrm{mg} / \mathrm{dl})$, a $120 \mathrm{~min}$ glucose of 7.8 to 11.1 $\mathrm{mmol} / \mathrm{l}(140$ to $199 \mathrm{mg} / \mathrm{dl})$ and/or $\mathrm{HbA}_{\mathrm{lc}}$ of 39 to $46 \mathrm{mmol} / \mathrm{mol}$ (5.7\% to $6.4 \%$ ), inclusive [11]. Stage 3 type 1 diabetes was defined using ADA criteria for diabetes mellitus [12]. The dose of glucose used in OGTTs was $1.75 \mathrm{~g} / \mathrm{kg}$ to a maximum of $75 \mathrm{~g}$. C-peptide was measured by radioimmunoassay in DPT-1 and for other studies using the TOSOH autoanalyser (TOSOH, South San Francisco, CA, USA). In TrialNet, DPT-1 and TEDDY, $\mathrm{HbA}_{1 \mathrm{c}}$ was measured using ion-exchange high-performance liquid chromatography on $\mathrm{TOSOH}$ autoanalysers and standardised using the Diabetes Control and Complications Trial reference method. $\mathrm{HbA}_{1 \mathrm{c}}$ measurements for Frlda were performed at the participant's local clinical laboratory.

Analyses The glmulti (v1.0.8) [24] and survival (v3.1-12) [25] packages of R software (v3.6.3; www.r-project.org) were used to build all possible single OGTT time point Cox proportional hazards regression models to predict progression from stage $1 / 2$ to stage 3 type 1 diabetes using all possible combinations of the inputs listed in ESM Table 1. Models were then ranked by their Akaike's information criterion (AIC) score. For each OGTT time point, the simplest model that was within 2 AIC units of the model with the lowest AIC score was selected for further testing. Coefficients for these models, named $\mathrm{M}_{0}, \mathrm{M}_{30}$, $\mathrm{M}_{60}, \mathrm{M}_{90}$ and $\mathrm{M}_{120}$, are presented in ESM Table 2. Model calibration testing was performed with the GreenwoodD'Agostino-Nam test using the GND.calib R function [26], where deciles with few events were integrated into the next decile, as appropriate, and $p>0.05$ considered no evidence of poor fit.

Equations for the DPTRS, DPTRS60, Index60 and $\mathrm{M}_{120}$ risk tools are provided below, where the units for BMI, age, glucose, C-peptide and $\mathrm{HbA}_{1 \mathrm{c}}$ are, respectively, $\mathrm{kg} / \mathrm{m}^{2}$, years, $\mathrm{mg} / \mathrm{dl}, \mathrm{ng} / \mathrm{ml}$ and percentage units. Sex was assigned a score of 1 for male and 2 for female, and IA-2A status assigned 0 for absent and 1 for present. Glucose is converted from $\mathrm{mmol} / \mathrm{l}$ to $\mathrm{mg} / \mathrm{dl}$ by multiplying by 18 ; C-peptide is converted from $\mathrm{nmol} / \mathrm{l}$ to $\mathrm{ng} / \mathrm{ml}$ by dividing by 3.00 ; and $\mathrm{HbA}_{1 \mathrm{c}}$ is converted from $\mathrm{mmol} / \mathrm{mol}$ to percentage units by adding 23.5 and then dividing by 10.93 .

DPTRS $=1.569 \times \log _{\mathrm{e}}(\mathrm{BMI})-0.056 \times($ age $)+0.00813 \times($ sum of glucose from 30 to $120 \mathrm{~min}$ ) $-0.0848 \times$ (sum of C-peptide from 30 to $120 \mathrm{~min})+0.476 \times \log _{\mathrm{e}}$ (fasting C-peptide) [16]
DPTRS60 $=1.364 \times \log _{\mathrm{e}}(\mathrm{BMI})-0.065 \times(\mathrm{age})+0.465 \times \log _{\mathrm{e}}$ (fasting C-peptide $)+0.019 \times(60 \mathrm{~min}$ glucose $)-0.311 \times(60 \mathrm{~min}$ C-peptide) [18]

Index60 $=0.3695 \times \log _{\mathrm{e}}($ fasting C-peptide $)+0.0165 \times(60 \mathrm{~min}$ glucose $)-0.3644 \times(60 \mathrm{~min}$ C-peptide $)$ [17]

$\mathrm{M}_{120}=0.448 \times(\mathrm{sex})+0.631 \times(\mathrm{IA}-2 \mathrm{~A})-0.0302 \times($ age $)+$ $0.0605 \times(\mathrm{BMI})+1.380 \times\left(\mathrm{HbA}_{1 \mathrm{c}}\right)+0.0265 \times(120 \mathrm{~min}$ glucose $)-$ $0.191 \times(120$ min C-peptide)

Prism software (v8.3.1g for Mac; GraphPad, San Diego, CA, USA) was used to perform Mann-Whitney tests for intergroup comparisons, to chart Kaplan-Meier survival curves of groups above and below the median value, and to compare the curves using the logrank (Mantel-Cox) test. AUC analysis of receiver operating characteristic (ROC) plots and comparisons of different prediction models were performed using the $p R O C$ package in $\mathrm{R}$ [27]. Calculations for sensitivity (TP/ $[T P+F N])$, specificity $(T N /[T N+F P])$ and accuracy $([T P+$ $T N] / N$ ) used the median value as the risk threshold, where $T P$, $T N, F P, F N$ and $N$ are true-positives, true-negatives, falsepositives, false-negatives and total number of participants, respectively.

Statement of informed consent Informed consent was obtained from all individual participants and, for children, their parents or legal guardians.

\section{Results}

Models to predict risk of progression from stage 1 or 2 to stage 3 type 1 diabetes were developed using data from 1208 TrialNet participants who screened positive to at least two of IAA, GADA, IA-2A and ZnT8A and underwent an OGTT at the same time or at their next study visit. The median [Q1, Q3] age of this 'training' population was 9.3 [6.2, 13.3] years and 56\% were male (Table 1). Five models, termed $\mathrm{M}_{0}, \mathrm{M}_{30}, \mathrm{M}_{60}, \mathrm{M}_{90}$ and $\mathrm{M}_{120}$, were developed using glucose and C-peptide measures obtained, respectively, at the $0,30,60,90$ and 120 min time points of the OGTT (ESM Table 2). These models also included age, sex, $\mathrm{HbA}_{1 \mathrm{c}}$ and IA-2A status, and all but $\mathrm{M}_{0}$ included BMI. Their performance characteristics in the TrialNet training population, together with those of DPTRS, DPTRS60 and Index60, are presented in Table 2.

Models were then validated using data from an independent TrialNet validation population of 864 participants (Table 1). Their median [Q1, Q3] duration of follow-up of $2.4[1.0,5.0]$ years after their first OGTT was significantly greater than the $1.8[0.8,3.2]$ years for the TrialNet training population $(p<0.0001)$, and the risk scores obtained from all 


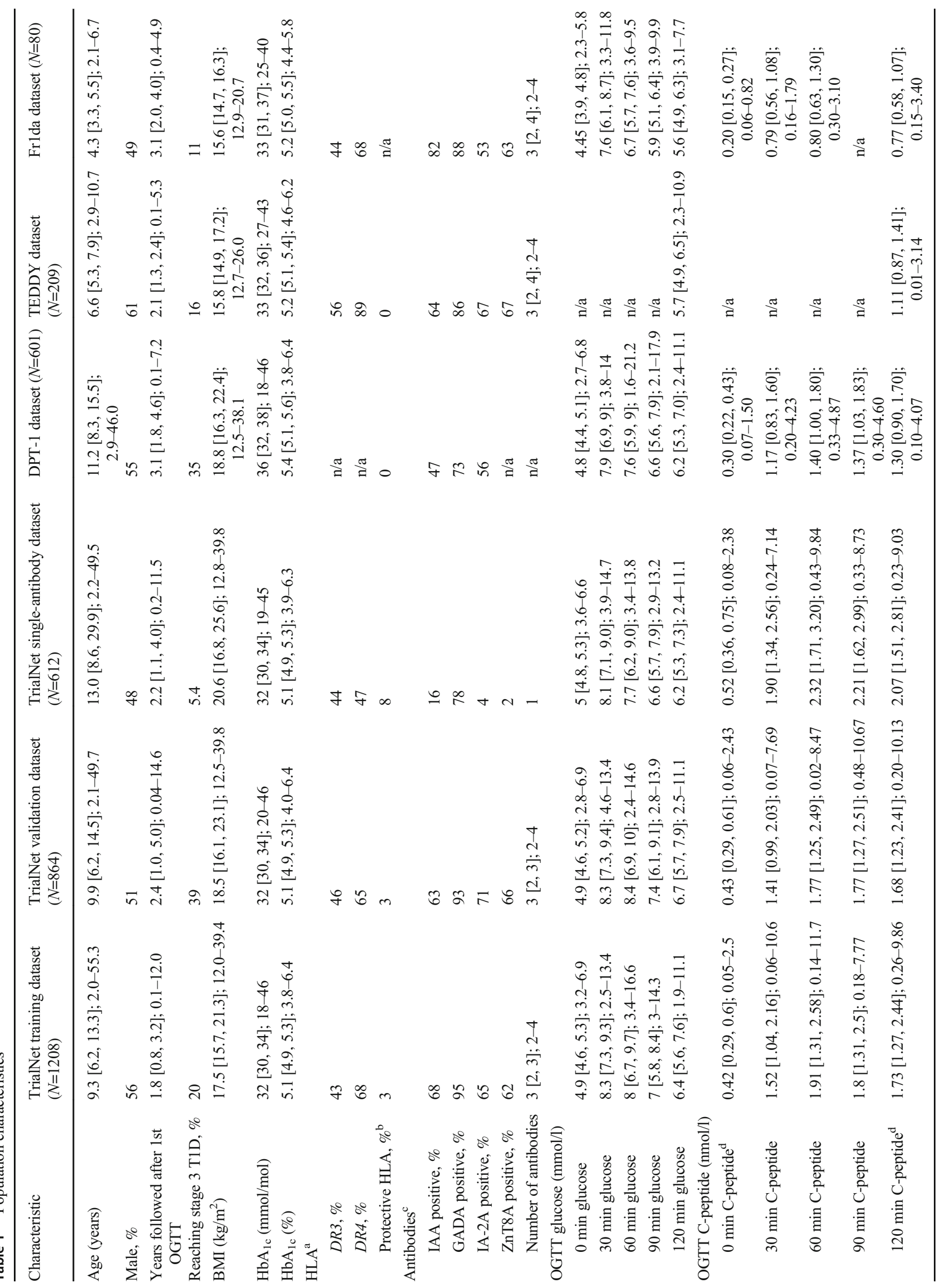




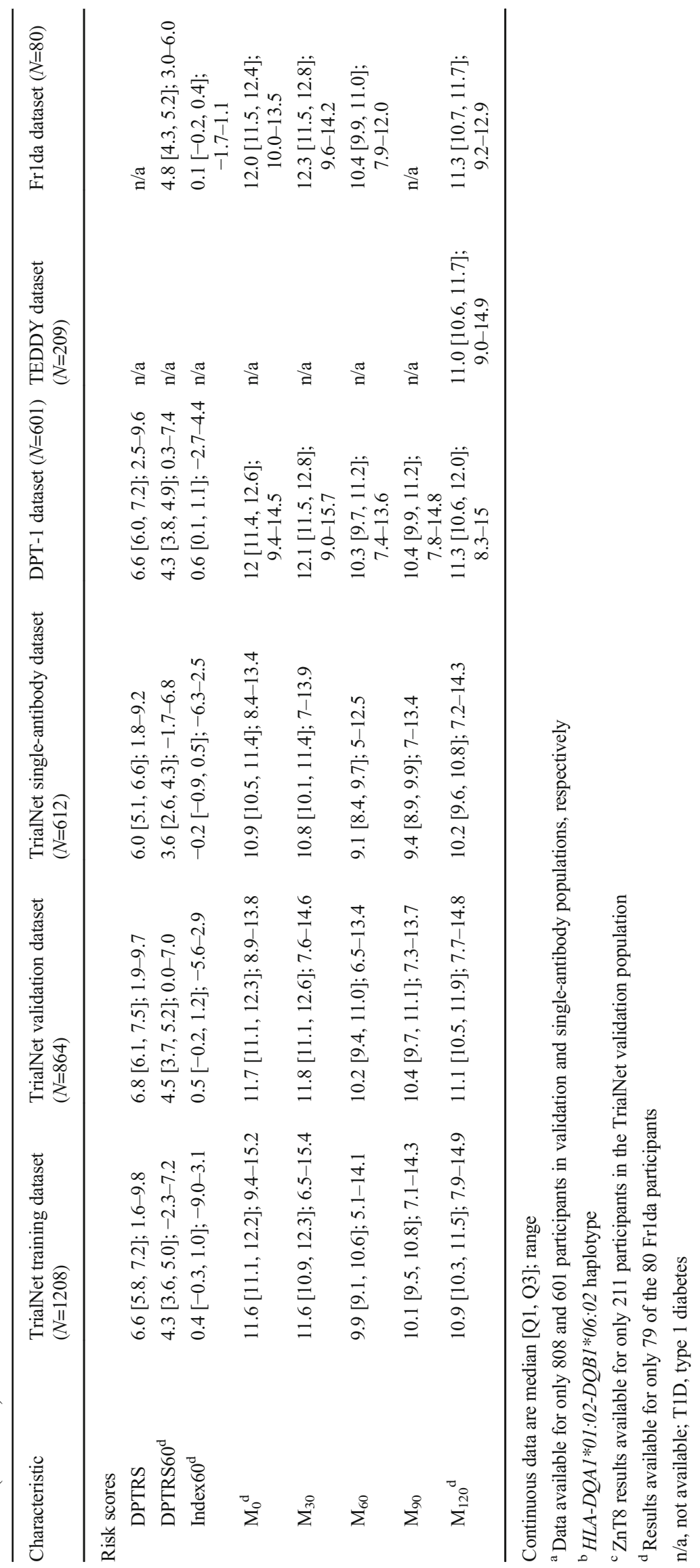


Table 2 Model performance in the TrialNet training and validation datasets

\begin{tabular}{|c|c|c|c|c|c|c|c|c|c|}
\hline Population & Model & AUC $(95 \%$ CI $)$ & $\begin{array}{l}p \mathrm{v} \\
\text { DPTRS }\end{array}$ & $\begin{array}{l}p \mathrm{v} \\
\text { DPTRS60 }\end{array}$ & $\begin{array}{l}p \mathrm{v} \\
\text { Index } 60\end{array}$ & $\begin{array}{l}p \mathrm{v} \\
\mathrm{AUC}_{\max }\end{array}$ & Sensitivity & Specificity & Accuracy \\
\hline \multirow[t]{8}{*}{ TrialNet training dataset } & $\mathrm{M}_{0}$ & $0.689(0.651,0.728)$ & 0.0019 & 0.0258 & 0.1905 & $<0.0001$ & 0.710 & 0.552 & 0.583 \\
\hline & $\mathrm{M}_{30}$ & $0.735(0.699,0.771)$ & 0.1306 & 0.8128 & 0.3828 & 0.0076 & 0.773 & 0.567 & 0.608 \\
\hline & $\mathrm{M}_{60}$ & $0.759(0.723,0.794)$ & 0.9027 & 0.0955 & 0.0038 & 0.4626 & 0.798 & 0.573 & 0.618 \\
\hline & $\mathrm{M}_{90}$ & $0.763(0.727,0.799)$ & 0.6550 & 0.0956 & 0.0069 & $\mathrm{n} / \mathrm{a}$ & 0.803 & 0.574 & 0.619 \\
\hline & $\mathrm{M}_{120}$ & $0.748(0.712,0.785)$ & 0.5301 & 0.5588 & 0.1191 & 0.0440 & 0.765 & 0.565 & 0.604 \\
\hline & DPTRS & $0.757(0.722,0.792)$ & $\mathrm{n} / \mathrm{a}$ & 0.0041 & 0.0009 & 0.6550 & 0.790 & 0.571 & 0.614 \\
\hline & DPTRS60 & $0.739(0.703,0.775)$ & 0.0041 & $\mathrm{n} / \mathrm{a}$ & 0.0446 & 0.0956 & 0.761 & 0.564 & 0.603 \\
\hline & Index60 & $0.720(0.683,0.758)$ & 0.0009 & 0.0446 & $\mathrm{n} / \mathrm{a}$ & 0.0069 & 0.731 & 0.557 & 0.591 \\
\hline \multirow{8}{*}{$\begin{array}{l}\text { TrialNet validation } \\
\text { dataset }\end{array}$} & $\mathrm{M}_{0}$ & $0.697(0.661,0.732)$ & 0.0018 & 0.0603 & 0.1876 & $<0.0001$ & 0.664 & 0.606 & 0.628 \\
\hline & $\mathrm{M}_{30}$ & $0.750(0.717,0.782)$ & 0.4574 & 0.3631 & 0.1273 & 0.2509 & 0.732 & 0.650 & 0.682 \\
\hline & $\mathrm{M}_{60}$ & $0.760(0.727,0.793)$ & 0.9916 & 0.0314 & 0.0031 & 0.9185 & 0.729 & 0.648 & 0.679 \\
\hline & $\mathrm{M}_{90}$ & $0.761(0.728,0.793)$ & 0.9648 & 0.0641 & 0.0148 & $\mathrm{n} / \mathrm{a}$ & 0.735 & 0.651 & 0.684 \\
\hline & $\mathrm{M}_{120}$ & $0.745(0.712,0.779)$ & 0.2682 & 0.5330 & 0.2284 & 0.0361 & 0.708 & 0.634 & 0.663 \\
\hline & DPTRS & $0.760(0.727,0.793)$ & $\mathrm{n} / \mathrm{a}$ & 0.0001 & 0.0009 & 0.9648 & 0.711 & 0.636 & 0.666 \\
\hline & DPTRS60 & $0.736(0.701,0.770)$ & 0.0001 & $\mathrm{n} / \mathrm{a}$ & 0.1992 & 0.0641 & 0.696 & 0.627 & 0.654 \\
\hline & Index60 & $0.725(0.689,0.760)$ & 0.0009 & 0.1992 & $\mathrm{n} / \mathrm{a}$ & 0.0148 & 0.708 & 0.634 & 0.663 \\
\hline
\end{tabular}

Within each population, $p$ v DPTRS, $p$ v DPTRS60, $p$ v Index60 and $p$ v AUC $\max$ are, respectively, $p$ values for statistical comparisons with DPTRS, DPTRS60, Index60 and the model with the highest AUC, without correction for multiple comparisons

n/a, not applicable

models were significantly higher. The abilities of the singletime-point models to predict disease progression in individuals who scored above and below the median value were compared with those of the DPTRS, DPTRS60 and Index60 (Fig. 1). After 5 years of follow-up, $\mathrm{M}_{30}, \mathrm{M}_{60}, \mathrm{M}_{90}$ and $\mathrm{M}_{120}$ predicted stage 3 type 1 diabetes in approximately $25 \%$ of participants who scored below the median and $65 \%$ of participants who scored above it. When compared with the DPTRS, the $\mathrm{M}_{30}, \mathrm{M}_{60}$ and $\mathrm{M}_{90}$ models enabled slightly greater separation of high- and low-risk groups. Comparisons with DPTRS60 and Index60 showed that $\mathrm{M}_{120}$, as well as $\mathrm{M}_{30}$, $\mathrm{M}_{60}$ and $\mathrm{M}_{90}$, enabled greater separation. However, the AUCs for ROC curves for $\mathrm{M}_{30}(0.750), \mathrm{M}_{60}(0.760), \mathrm{M}_{90}$ (0.761) and $\mathrm{M}_{120}(0.745)$ did not differ significantly from the AUC of 0.760 for the DPTRS (Table 2). Measures of model sensitivity, specificity and accuracy are also presented in Table 2. The goodness of fit of each of the single-time-point models was confirmed using the Greenwood-D'AgostinoNam calibration test.

We chose to focus analyses of additional at-risk populations on $\mathrm{M}_{120}$ because it performed well relative to DPTRS, DPTRS60 and Index60, and because it is most relevant for pre-symptomatic screening, where $120 \mathrm{~min}$ sampling is mandatory for type 1 diabetes staging, and therefore routinely performed for autoantibody-positive people. For completeness, the performance characteristics of all models in additional populations are presented in Table 3 .
$\mathrm{M}_{120}$ reliably stratified stage 1 (normal glucose tolerance and $\mathrm{HbA}_{1 c} ; n=513$ ) and stage 2 (fasting glucose 5.6 to 7.0 $\mathrm{mmol} / \mathrm{l} ; 30,60$ or $90 \mathrm{~min}$ glucose $>11.1 \mathrm{mmol} / \mathrm{l} ; 120 \mathrm{~min}$ glucose 7.8 to $11.1 \mathrm{mmol} / \mathrm{l}$; and/or $\mathrm{HbA}_{1 \mathrm{c}} 39$ to $46 \mathrm{mmol} / \mathrm{mol}$; $n=351$ ) subgroups of the TrialNet validation population, to a degree comparable to that of the DPTRS (Fig. 2a-d, Table 3).

$\mathrm{M}_{120}$ was then tested for its ability to stratify 612 TrialNet participants who tested positive to only a single autoantibody and were therefore not formally diagnosed with presymptomatic type 1 diabetes, which requires two or more autoantibody specificities [11]. This group included 89 participants $(15 \%)$ who later developed multiple antibodies in TrialNet and whose data from a subsequent visit contributed to the TrialNet training $(n=72)$ or validation $(n=17)$ datasets. When compared with the two multiple-antibody datasets, the TrialNet single-antibody population had a lower rate of disease progression and lower risk scores (Table 1). Nonetheless, $\mathrm{M}_{120}$ could stratify this population into highand low-risk subgroups, albeit less effectively than the DPTRS (Fig. 2e, f). The AUC of $\mathrm{M}_{60}$ in this population exceeded the AUCs of DPTRS, DPTRS60 and Index60, but the differences were not statistically significant (Table 3).

DPT-1 data were obtained from 601 relatives [21, 22]. When compared with the TrialNet training and validation populations, the earlier DPT-1 population had a higher age and $\mathrm{HbA}_{1 \mathrm{c}}$; lower incidence of IAA, GADA and IA-2A; and a lower C-peptide at all OGTT time points (Table 1). When 
Fig. 1 Survival curves in the TrialNet validation population. The percentage of participants free of progression to stage 3 type 1 diabetes with $95 \%$ CI is shown, stratified into high (red) and low (blue) risk according to the median value. $(\mathbf{a}-\mathbf{h})$ Risk scores calculated by the DPTRS, DPTRS60, Index60, $\mathrm{M}_{0}, \mathrm{M}_{30}$, $\mathrm{M}_{60}, \mathrm{M}_{90}$ and $\mathrm{M}_{120}$ models, respectively. The $p$ values for curve comparisons are provided and numbers at risk are provided beneath each graph a
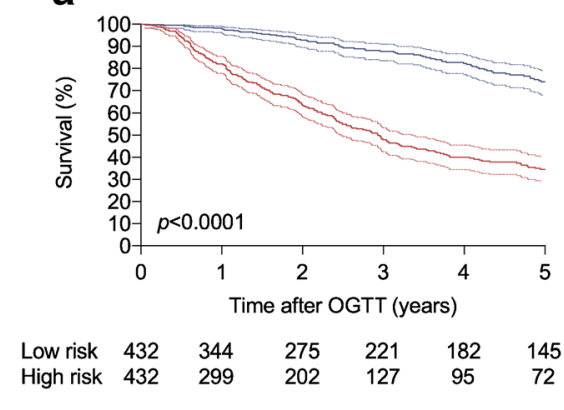

C

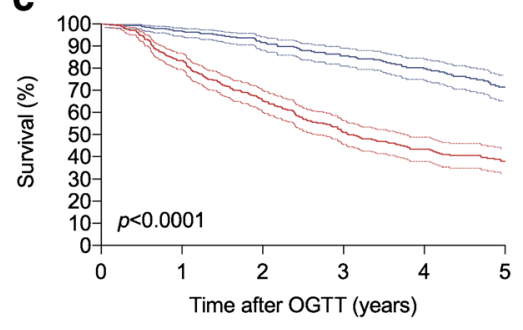

$\begin{array}{lllllll}\text { Low risk } & 432 & 336 & 263 & 206 & 169 & 130\end{array}$

e

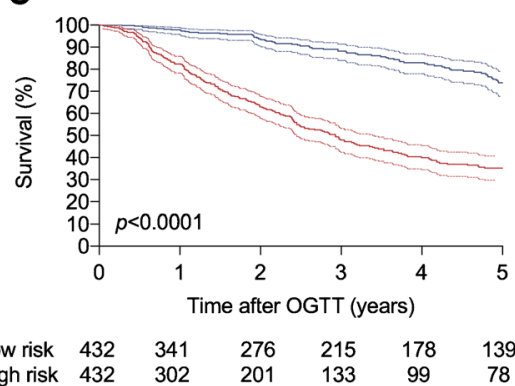

g

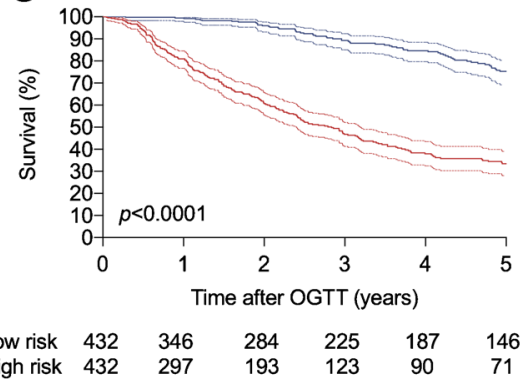

b

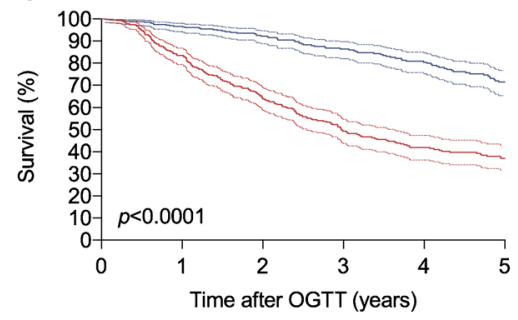

$\begin{array}{lllllll}\text { Low risk } & 432 & 340 & 273 & 215 & 177 & 136\end{array}$ $\begin{array}{lllllll}\text { High risk } & 432 & 303 & 204 & 133 & 100 & 81\end{array}$

d

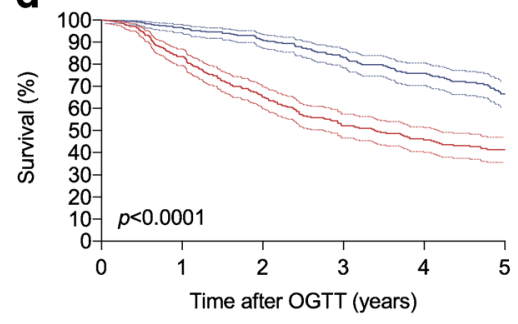
$\begin{array}{llllllr}\text { High risk } & 432 & 303 & 204 & 133 & 100 & 81\end{array}$

f

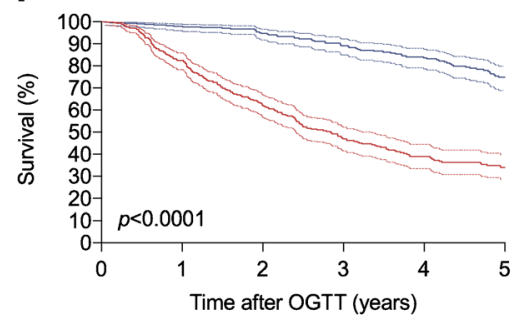
$\begin{array}{lllllll}\text { Low risk } & 432 & 341 & 282 & 223 & 186 & 146 \\ \text { High risk } & 432 & 302 & 195 & 125 & 91 & 71\end{array}$

h

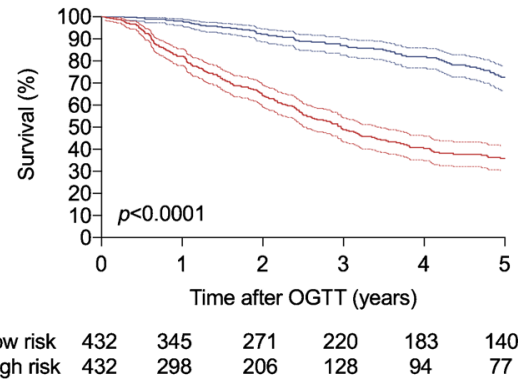

DPT-1 was stratified by the median value into high- and lowrisk groups, $\mathrm{M}_{120}$ enabled significant separation, with $32 \%$ of low-risk and $54 \%$ of high-risk participants progressing to stage 3 type 1 diabetes after 5 years (Fig. 2h). This degree of separation was lower than was observed in the TrialNet validation population (Fig. 1g), and also lower than could be achieved by the DPTRS, which predicted disease progression in $15 \%$ of low-risk and $70 \%$ of high-risk participants (Fig. 2f). The DPTRS AUC was significantly greater than the AUC of any other single-time-point model (Table 3 ).
The TEDDY study screened newborn, genetically atrisk children for islet autoantibodies every 3 to 6 months from age 3 months to 15 years. Multiple-autoantibodypositive children $(N=209$; Table 1$)$ underwent limited OGTT, wherein a single venous sample for glucose and C-peptide was collected $120 \mathrm{~min}$ after glucose challenge. In this group, $\mathrm{M}_{120}$ reliably predicted progression to stage 3 disease using the median value of 11.0 as the risk threshold (Fig. 2i), and its AUC was 0.865 (Table 3). 
Table 3 Model performance in other populations

\begin{tabular}{|c|c|c|c|c|c|c|c|}
\hline Population & Model & AUC (95\% CI) & $p$ v DPTRS & $p \mathrm{v} \mathrm{AUC}_{\max }$ & Sensitivity & Specificity & Accuracy \\
\hline \multirow[t]{8}{*}{ TrialNet validation dataset, stage $1 \mathrm{~T} 1 \mathrm{D}$} & $\mathrm{M}_{0}$ & $0.665(0.614,0.715)$ & 0.7813 & 0.0334 & 0.671 & 0.566 & 0.595 \\
\hline & $\mathrm{M}_{30}$ & $0.698(0.648,0.747)$ & 0.0835 & $\mathrm{n} / \mathrm{a}$ & 0.729 & 0.587 & 0.626 \\
\hline & $\mathrm{M}_{60}$ & $0.682(0.630,0.734)$ & 0.2214 & 0.2227 & 0.707 & 0.579 & 0.614 \\
\hline & $\mathrm{M}_{90}$ & $0.672(0.621,0.723)$ & 0.4823 & 0.0865 & 0.693 & 0.574 & 0.606 \\
\hline & $\mathrm{M}_{120}$ & $0.651(0.598,0.704)$ & 0.8405 & 0.0075 & 0.671 & 0.566 & 0.595 \\
\hline & DPTRS & $0.656(0.603,0.709)$ & $\mathrm{n} / \mathrm{a}$ & 0.0835 & 0.636 & 0.552 & 0.575 \\
\hline & DPTRS60 & $0.651(0.598,0.704)$ & 0.6032 & 0.0601 & 0.657 & 0.560 & 0.587 \\
\hline & Index60 & $0.636(0.580,0.692)$ & 0.2385 & 0.0211 & 0.629 & 0.550 & 0.571 \\
\hline \multirow[t]{8}{*}{ TrialNet validation dataset, stage $2 \mathrm{~T} 1 \mathrm{D}$} & $\mathrm{M}_{0}$ & $0.663(0.604,0.721)$ & 0.0007 & 0.0007 & 0.603 & 0.638 & 0.618 \\
\hline & $\mathrm{M}_{30}$ & $0.728(0.675,0.781)$ & 0.0302 & 0.0302 & 0.638 & 0.684 & 0.658 \\
\hline & $\mathrm{M}_{60}$ & $0.764(0.714,0.814)$ & 0.3681 & 0.3681 & 0.678 & 0.737 & 0.704 \\
\hline & $\mathrm{M}_{90}$ & $0.775(0.727,0.823)$ & 0.7585 & 0.7585 & 0.658 & 0.711 & 0.681 \\
\hline & $\mathrm{M}_{120}$ & $0.753(0.703,0.803)$ & 0.2344 & 0.2344 & 0.643 & 0.691 & 0.664 \\
\hline & DPTRS & $0.781(0.733,0.830)$ & $\mathrm{n} / \mathrm{a}$ & $\mathrm{n} / \mathrm{a}$ & 0.688 & 0.750 & 0.715 \\
\hline & DPTRS60 & $0.741(0.689,0.794)$ & $<0.0001$ & $<0.0001$ & 0.673 & 0.730 & 0.698 \\
\hline & Index60 & $0.738(0.686,0.790)$ & 0.0075 & 0.0075 & 0.663 & 0.717 & 0.687 \\
\hline \multirow[t]{8}{*}{ TrialNet single-antibody dataset } & $\mathrm{M}_{0}$ & $0.650(0.549,0.752)$ & 0.0394 & 0.0006 & 0.727 & 0.513 & 0.525 \\
\hline & $\mathrm{M}_{30}$ & $0.760(0.667,0.853)$ & 0.9761 & 0.1302 & 0.818 & 0.518 & 0.534 \\
\hline & $\mathrm{M}_{60}$ & $0.799(0.708,0.890)$ & 0.0995 & $\mathrm{n} / \mathrm{a}$ & 0.818 & 0.518 & 0.534 \\
\hline & $\mathrm{M}_{90}$ & $0.768(0.668,0.867)$ & 0.7671 & 0.0588 & 0.848 & 0.520 & 0.538 \\
\hline & $\mathrm{M}_{120}$ & $0.701(0.594,0.808)$ & 0.0448 & 0.0001 & 0.727 & 0.513 & 0.525 \\
\hline & DPTRS & $0.761(0.652,0.870)$ & $\mathrm{n} / \mathrm{a}$ & 0.0995 & 0.758 & 0.515 & 0.528 \\
\hline & DPTRS60 & $0.752(0.642,0.862)$ & 0.4518 & 0.0585 & 0.788 & 0.516 & 0.531 \\
\hline & Index60 & $0.784(0.678,0.889)$ & 0.3086 & 0.4459 & 0.818 & 0.518 & 0.534 \\
\hline \multirow[t]{8}{*}{ DPT-1 } & $\mathrm{M}_{0}$ & $0.611(0.564,0.658)$ & $<0.0001$ & $<0.0001$ & 0.591 & 0.550 & 0.564 \\
\hline & $\mathrm{M}_{30}$ & $0.696(0.653,0.739)$ & $<0.0001$ & $<0.0001$ & 0.683 & 0.598 & 0.627 \\
\hline & $\mathrm{M}_{60}$ & $0.741(0.700,0.781)$ & 0.0009 & 0.0009 & 0.726 & 0.621 & 0.657 \\
\hline & $\mathrm{M}_{90}$ & $0.717(0.675,0.760)$ & $<0.0001$ & $<0.0001$ & 0.697 & 0.606 & 0.637 \\
\hline & $\mathrm{M}_{120}$ & $0.694(0.649,0.738)$ & $<0.0001$ & $<0.0001$ & 0.663 & 0.588 & 0.614 \\
\hline & DPTRS & $0.800(0.762,0.838)$ & $\mathrm{n} / \mathrm{a}$ & $\mathrm{n} / \mathrm{a}$ & 0.813 & 0.667 & 0.717 \\
\hline & DPTRS60 & $0.792(0.754,0.829)$ & 0.2612 & 0.2612 & 0.798 & 0.659 & 0.707 \\
\hline & Index60 & $0.761(0.720,0.801)$ & 0.0029 & 0.0029 & 0.745 & 0.631 & 0.671 \\
\hline TEDDY & $\mathrm{M}_{120}$ & $0.865(0.792,0.938)$ & $\mathrm{n} / \mathrm{a}$ & $\mathrm{n} / \mathrm{a}$ & 0.909 & 0.580 & 0.632 \\
\hline \multirow[t]{6}{*}{ Fr1da } & $\mathrm{M}_{0}$ & $0.710(0.549,0.871)$ & $\mathrm{n} / \mathrm{a}$ & 0.7334 & 0.667 & 0.529 & 0.544 \\
\hline & $\mathrm{M}_{30}$ & $0.668(0.510,0.826)$ & $\mathrm{n} / \mathrm{a}$ & 0.2543 & 0.778 & 0.535 & 0.563 \\
\hline & $\mathrm{M}_{60}$ & $0.615(0.438,0.793)$ & $\mathrm{n} / \mathrm{a}$ & 0.0338 & 0.667 & 0.521 & 0.538 \\
\hline & $\mathrm{M}_{120}$ & $0.742(0.596,0.889)$ & $\mathrm{n} / \mathrm{a}$ & $\mathrm{n} / \mathrm{a}$ & 0.889 & 0.557 & 0.595 \\
\hline & DPTRS60 & $0.567(0.340,0.794)$ & $\mathrm{n} / \mathrm{a}$ & 0.0019 & 0.333 & 0.486 & 0.468 \\
\hline & Index60 & $0.638(0.440,0.835)$ & $\mathrm{n} / \mathrm{a}$ & 0.0006 & 0.333 & 0.486 & 0.468 \\
\hline
\end{tabular}

Within each population, $p \mathrm{v}$ DPTRS and $p$ v AUC $\mathrm{max}_{\text {ax }}$ are, respectively, $p$ values for statistical comparisons with DPTRS and the model with the highest AUC, without correction for multiple comparisons

$\mathrm{n} / \mathrm{a}$, not applicable; T1D, type 1 diabetes

Finally, models were tested with data from 80 multiple-autoantibody-positive children participating in the Bavarian Fr1da general population screening programme [7] (Table 1). These children underwent an
OGTT with sampling every $30 \mathrm{~min}$. However, because C-peptide was not measured at $90 \mathrm{~min}$, neither DPTRS nor $\mathrm{M}_{90}$ could be calculated. Based on the median score of 11.3 (Table 1), $\mathrm{M}_{120}$ significantly stratified the 
Fig. 2 DPTRS and $\mathrm{M}_{120}$ survival curves in TrialNet sub-

populations, DPT-1, TEDDY and Fr1da. Survival curves show the percentage of participants free of progression to stage 3 type 1 diabetes with $95 \%$ CI predicted by DPTRS (a, c, e, g) and $\mathrm{M}_{120}$ $(\mathbf{b}, \mathbf{d}, \mathbf{f}, \mathbf{h}, \mathbf{i}, \mathbf{j})$. Populations shown are the stage $1(\mathbf{a}, \mathbf{b})$ and stage 2 (c, d) subgroups of the TrialNet validation population, the TrialNet single-antibody population (e, f), DPT-1 (g, h), TEDDY (i) and Fr1da (j). Stratification into high (red) and low (blue) risk groups was according to the median value in each population. The $p$ values for curve comparisons are provided and numbers at risk are provided beneath each graph a
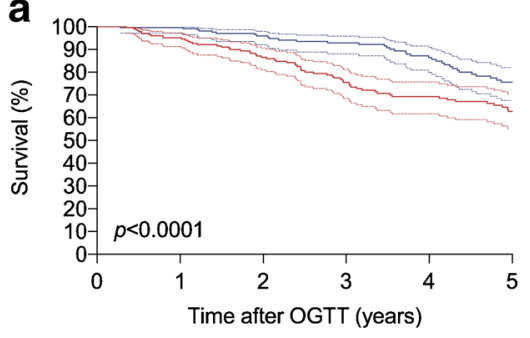

$\begin{array}{lllllll}\text { Low risk } & 257 & 210 & 167 & 140 & 112 & 84 \\ \text { High risk } & 256 & 194 & 153 & 112 & 92 & 76\end{array}$

C

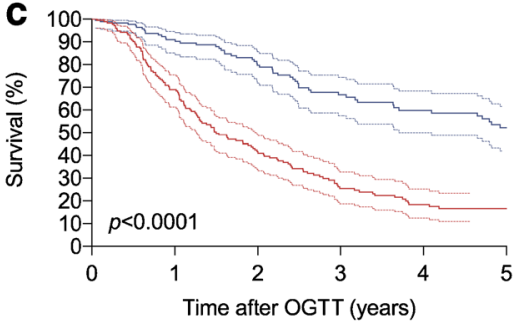

$\begin{array}{lllllll}\text { Low risk } & 176 & 130 & 95 & 61 & 51 & 40 \\ \text { High risk } & 175 & 109 & 62 & 35 & 22 & 17\end{array}$
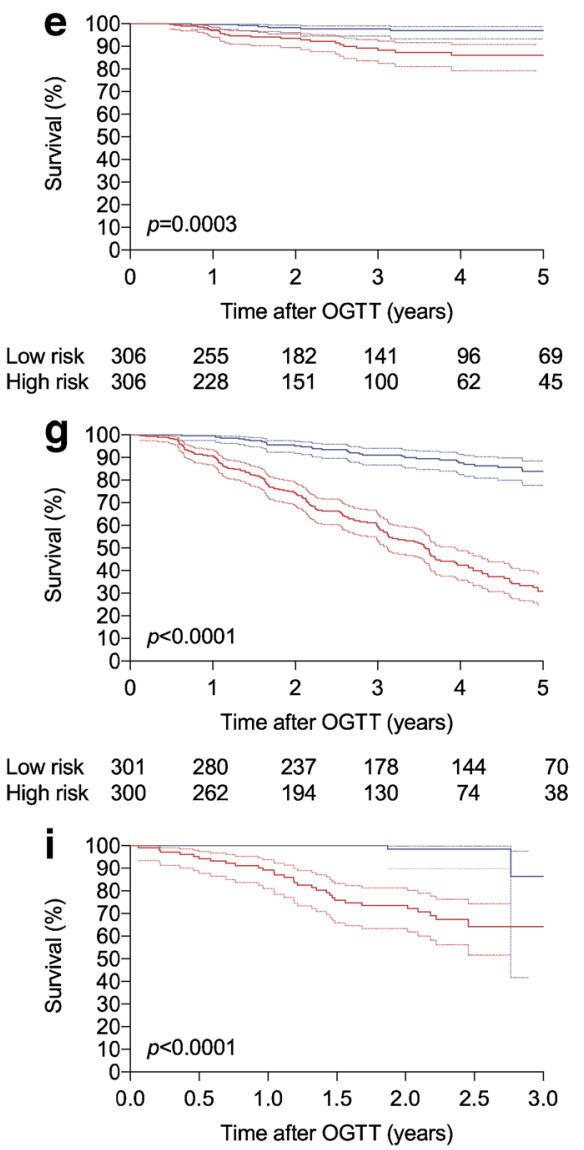

$\begin{array}{lrrrrrrr}\text { Low risk } & 105 & 103 & 93 & 81 & 58 & 26 & 6 \\ \text { High risk } & 104 & 98 & 83 & 69 & 57 & 17 & 2\end{array}$ b

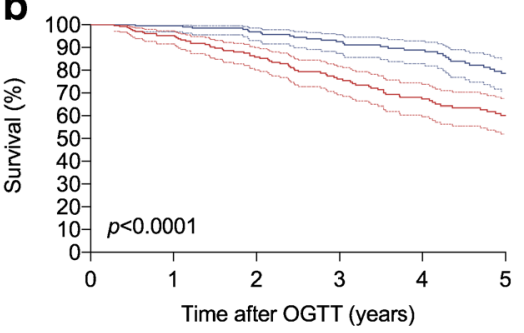

$\begin{array}{lllllll}\text { Low risk } & 257 & 202 & 169 & 136 & 111 & 88 \\ \text { High risk } & 256 & 202 & 151 & 116 & 93 & 72\end{array}$

d

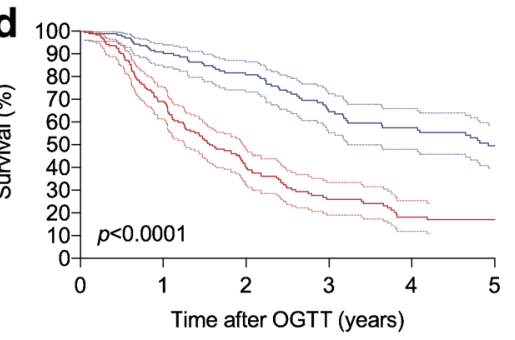

$\begin{array}{lllllll}\text { Low risk } & 176 & 129 & 99 & 65 & 55 & 42 \\ \text { High risk } & 175 & 110 & 58 & 31 & 18 & 15\end{array}$

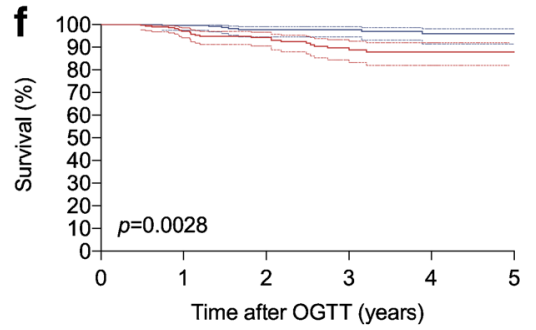

$\begin{array}{lllllll}\text { Low risk } & 306 & 247 & 169 & 133 & 92 & 70\end{array}$

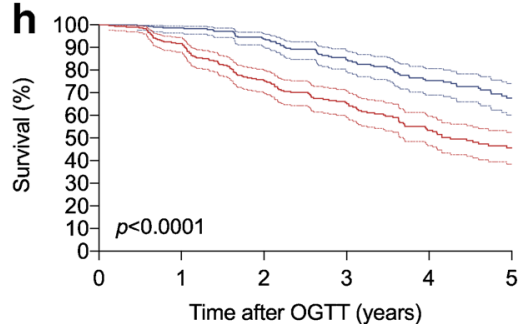

$\begin{array}{lllllll}\text { Low risk } & 301 & 280 & 237 & 173 & 126 & 62\end{array}$

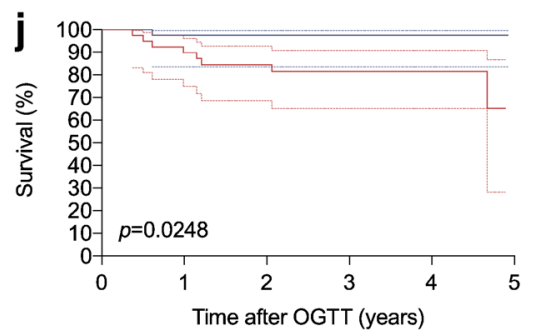

$\begin{array}{lllllcl}\text { Low risk } & 40 & 39 & 32 & 22 & 9 & 1 \\ \text { High risk } & 39 & 36 & 30 & 24 & 15 & 1\end{array}$ relatively small population of Frlda participants (Fig. $2 \mathrm{j}$ ). The $\mathrm{M}_{120}$ AUC of 0.742 was significantly greater than the AUCs for $\mathrm{M}_{60}(0.615)$, DPTRS60 (0.567) and Index60 (0.638) (Table 3).

\section{Discussion}

We describe models to predict progression to insulindependent type 1 diabetes that are simpler than the previously 
validated DPTRS, DPTRS60 and Index60 risk scores and yet have comparable performance in the contemporary TrialNet and Frlda populations. The models incorporated sex, age, BMI, $\mathrm{HbA}_{1 \mathrm{c}}$ and IA-2A status in combinations with glucose and C-peptide measures that are the basis of the DPTRS, DPTRS60 and Index60. In contrast to DPTRS, DPTRS60 and Index60, the new models focus on a single-time-point blood sample during the OGTT, decreasing the cost associated with analyte measurement. In addition, they do not require venous cannulation, which adds complexity and discomfort, particularly in young children. $\mathrm{M}_{60}$ and $\mathrm{M}_{90}$ were the most accurate single-time-point models in TrialNet. However, $\mathrm{M}_{120}$, based on a $120 \mathrm{~min}$ blood sample that is routinely used to stage type 1 diabetes, performed well in all populations other than DPT-1 and might therefore be best suited to current screening programmes of at-risk relatives [6] and, potentially, the general population $[7,8]$.

The universal use of sex, $\mathrm{HbA}_{1 \mathrm{c}}$ and IA-2A status by all single-time-point models suggests that their incorporation into DPTRS and DPTRS60 might improve the performance of these models, and that the performance of Index 60 could be augmented by these measures together with age and BMI. Age, $\mathrm{HbA}_{1 \mathrm{c}}$ and IA-2A status are recognised risk factors for disease progression $[7,14,28-30]$, and sex and BMI have been associated with progression to stage 3 diabetes in some [16, 30, 31], but not all [29], studies of autoantibody-positive people. Notably, although HLA-DR3 and -DR4 alleles have been described as predictors of progression from stage 1 to stage 3 disease in the TEDDY study [31], neither contributed to model performance.

Type 1 diabetes disease staging was introduced to educate the medical and lay communities about pre-symptomatic type 1 diabetes and the potential for its prevention using immune therapy [11]. Disease stages 1 and 2 also help classify the risk of progression to insulin dependence and have been used to define eligibility for prevention trials. Because disease staging requires a 120 min sample, $M_{120}$ could be readily incorporated into current clinical workflows, thereby helping to improve clinical trial efficiency and, potentially, the identification of autoantibody-positive individuals at greatest risk of ketoacidosis, for whom education about symptoms of hyperglycaemia and close follow-up should be provided. It could also be used to identify individuals approaching insulin dependence who are currently best suited to receive immune therapy [4] as well as to identify high-risk single-antibody-positive individuals who would not currently meet entry criteria for TrialNet prevention trials. The key disadvantage of $\mathrm{M}_{120}$ compared with other single-time-point models is the time required to do the test, but perhaps this could be shortened if participants were provided with a kit that enabled them to record home fasting capillary blood glucose (for the purposes of type 1 diabetes staging), ingest glucose and then time their arrival to a collection centre for a single blood draw 120 min later.
In the TrialNet populations studied, the AUCs for the $\mathrm{M}_{60}$ and $\mathrm{M}_{90}$ models were greater than the AUCs of the other single-time-point models, and $\mathrm{M}_{60}$ performed better than $\mathrm{M}_{0}, \mathrm{M}_{30}, \mathrm{M}_{90}$ and $\mathrm{M}_{120}$ in DPT-1. These findings accord with a TrialNet study which demonstrated that a biphasic oral glucose response with a nadir at 60 or 90 min was associated with a low risk of disease progression [32], and the analysis of a combined DPT- 1 and TrialNet dataset that formed the basis of the Index60 score, which identified 60 min measures of glucose and C-peptide as the strongest univariate predictors of stage 3 disease [17]. Overall, this suggests $\mathrm{M}_{60}$ could be used instead of DPTRS in TrialNet to simplify and decrease the cost of risk assessment, particularly if the $60 \mathrm{~min}$ glucose were used to diagnose diabetes mellitus, as suggested by other TrialNet studies $[17,18]$. However, there has been a longstanding requirement for a 120 min glucose to diagnose diabetes mellitus [12], which is likely to endure. Furthermore, the very high $\mathrm{M}_{120}$ AUC of 0.865 in TEDDY and the superior performance of $\mathrm{M}_{120}$ relative to other models in Frlda suggest that 120 min sampling might be optimal for disease staging and risk stratification outside of TrialNet.

When tested in DPT-1, the models developed in this study were less accurate than DPTRS, DPTRS60 and Index60. This discrepancy is at least in part because these three multipletime-point models were developed using DPT-1 data [16-18], which differed from TrialNet with respect to age, autoantibody prevalence, $\mathrm{HbA}_{1 \mathrm{c}}$ and C-peptide. These population differences might be explained by the requirement in DPT-1 for participants to screen positive for islet cell antibodies by indirect immunofluorescence, the use of different autoantibody and C-peptide assays in DPT-1 that at times were performed many years after sample collection and, potentially, by changes in the contribution of environment to disease risk since the start of DPT-1 [33].

Several caveats should be mentioned. First, because TrialNet, TEDDY and Frlda enrolled mostly individuals of European descent and used similar laboratory methods to measure C-peptide and $\mathrm{HbA}_{1 \mathrm{c}}$, the performance of the models in different contexts remains unproven. In addition, the Frlda population was relatively small and therefore under-powered to assess the validity of all of the models, and thus further testing will be needed to confirm the utility of $\mathrm{M}_{120}$ in a general population setting. Finally, the thresholds used to define high and low risk for survival analyses were based on median values, which may not be optimal for specific populations. This being said, the DPTRS threshold of 6.8 used to define risk of progression to stage 3 type 1 diabetes in the TrialNet validation population was between the previously recommended thresholds of 6.5 for low risk [34] and 7.0 to 7.5 for high risk $[34,35]$. Therefore, the $\mathrm{M}_{120}$ score of 11.1 used to stratify the TrialNet validation population would appear to be a reasonable threshold to apply to future TrialNet participants with stage 1 or 2 type 1 diabetes. 
In summary, unbiased selection methods were applied to TrialNet data to develop equations to predict disease progression in pre-symptomatic type 1 diabetes. The $\mathrm{M}_{120}$ model, based on a single blood draw at $120 \mathrm{~min}$ of the OGTT, was identified as a comparably accurate yet more practical tool than the DPTRS, DPTRS60 or Index60. Its validity in different at-risk populations and its operational simplicity make $\mathrm{M}_{120}$ broadly applicable to current screening programmes and, potentially, for more routine clinical use with the advent of disease-modifying therapies.

Supplementary Information The online version of this article (https://doi. org/10.1007/s00125-021-05523-2) contains peer-reviewed but unedited supplementary material.

Acknowledgements We are grateful to the many participants, study investigators and coordinators who contributed to data used for this work, and to A. Gorelik (University of Melbourne, Australia) and D. Cuthbertson (University of Florida, USA), who performed a statistical review of the manuscript. The TrialNet, DPT-1 and TEDDY studies were supported by the National Institute of Diabetes and Digestive and Kidney Diseases (NIDDK). The data from these studies were supplied by the NIDDK Central Repositories. This manuscript was not prepared in collaboration with the investigators of the DPT-1 and TEDDY studies and does not necessarily reflect the opinions or views of the DPT-1 and TEDDY studies, the NIDDK Central Repositories or the NIDDK.

Data availability Data for TrialNet, TEDDY and DPT-1 can be obtained from the NIDDK data repository (https://repository.niddk.nih.gov/ home/). Frlda data are available upon reasonable request from A.-G. Ziegler, Institute of Diabetes Research, Helmholtz Zentrum München, German Research Center for Environmental Health, MunichNeuherberg, Germany.

Funding Open access funding provided by Lund University. This work was supported by JDRF (1-SRA-2020-900 to JMW and PGC) and the Australian National Health and Medical Research Council (NHMRC) (Program Grant APP 1150425 and Leadership Investigator Grant APP 1173945 to LCH). This work was made possible through Victorian State Government Operational Infrastructure Support and the Australian NHMRC Research Institute Infrastructure Support Scheme.

We acknowledge the support of the Type 1 Diabetes TrialNet Study Group, which identified study participants and provided samples and follow-up data for this study. The Type 1 Diabetes TrialNet Study Group is a clinical trials network funded by the National Institutes of Health $(\mathrm{NIH})$ through the National Institute of Diabetes and Digestive and Kidney Diseases, the National Institute of Allergy and Infectious Diseases and The Eunice Kennedy Shriver National Institute of Child Health and Human Development, through the cooperative agreements U01 DK061010, U01 DK061034, U01 DK061042, U01 DK061058, U01 DK085453, U01 DK085461, U01 DK085465, U01 DK085466, U01 DK085476, U01 DK085499, U01 DK085504, U01 DK085509, U01 DK103180, U01 DK103153, U01 DK103266, U01 DK103282, U01 DK106984, U01 DK106994, U01 DK107013, U01 DK107014, UC4 DK106993, UC4 DK11700901 and U01 DK106693-02, and JDRF. The contents of this article are solely the responsibility of the authors and do not necessarily represent the official views of the NIH or JDRF.
The Frlda study was supported by grants from LifeScience-Stiftung (HMGU 2014.01 and HMGU 2016.01), JDRF International (1-SRA2014-310-M-R and 3-SRA-2015-72-M-R), the Bavarian State Ministry of Health and Care (Gesund.Leben.Bayern, LP00228), The Leona M. and Harry B. Helmsley Charitable Trust (G-1911-03274), Deutsche DiabetesStiftung (364/ 11/14) and the German Federal Ministry of Education and Research to the German Center for Diabetes Research (DZD e.V.).

Authors' relationships and activities The authors declare that there are no relationships or activities that might bias, or be perceived to bias, their work.

Contribution statement NGB and JMW conceived the study. All authors contributed to data collation and interpretation. NGB, CSNL-W-S and JMW performed statistical analyses and drafted the manuscript, which all authors revised and approved. JMW takes responsibility for the integrity of the data and the accuracy of the data analysis.

Open Access This article is licensed under a Creative Commons Attribution 4.0 International License, which permits use, sharing, adaptation, distribution and reproduction in any medium or format, as long as you give appropriate credit to the original author(s) and the source, provide a link to the Creative Commons licence, and indicate if changes were made. The images or other third party material in this article are included in the article's Creative Commons licence, unless indicated otherwise in a credit line to the material. If material is not included in the article's Creative Commons licence and your intended use is not permitted by statutory regulation or exceeds the permitted use, you will need to obtain permission directly from the copyright holder. To view a copy of this licence, visit http://creativecommons.org/licenses/by/4.0/.

\section{References}

1. Steck AK, Larsson HE, Liu X et al (2017) Residual beta-cell function in diabetes children followed and diagnosed in the TEDDY study compared to community controls. Pediatr Diabetes 18(8): 794-802. https://doi.org/10.1111/pedi.12485

2. Hekkala AM, Ilonen J, Toppari J, Knip M, Veijola R (2018) Ketoacidosis at diagnosis of type 1 diabetes: Effect of prospective studies with newborn genetic screening and follow up of risk children. Pediatr Diabetes 19(2):314-319. https://doi.org/10.1111/pedi. 12541

3. Winkler C, Schober E, Ziegler AG, Holl RW (2012) Markedly reduced rate of diabetic ketoacidosis at onset of type 1 diabetes in relatives screened for islet autoantibodies. Pediatr Diabetes 13(4): 308-313. https://doi.org/10.1111/j.1399-5448.2011.00829.x

4. Herold KC, Bundy BN, Long SA et al (2019) An Anti-CD3 Antibody, Teplizumab, in Relatives at Risk for Type 1 Diabetes. N Engl J Med 381(7):603-613. https://doi.org/10.1056/ NEJMoa1902226

5. Krischer JP, Schatz DA, Bundy B, Skyler JS, Greenbaum CJ (2017) Effect of Oral Insulin on Prevention of Diabetes in Relatives of Patients With Type 1 Diabetes: A Randomized Clinical Trial. JAMA 318(19):1891-1902. https://doi.org/10. 1001/jama.2017.17070

6. Bingley PJ, Wherrett DK, Shultz A, Rafkin LE, Atkinson MA, Greenbaum CJ (2018) Type 1 Diabetes TrialNet: A Multifaceted Approach to Bringing Disease-Modifying Therapy to Clinical Use in Type 1 Diabetes. Diabetes Care 41(4):653-661. https://doi.org/ $10.2337 / \mathrm{dc} 17-0806$ 
7. Ziegler AG, Kick K, Bonifacio E et al (2020) Yield of a Public Health Screening of Children for Islet Autoantibodies in Bavaria, Germany. JAMA 323(4):339-351. https://doi.org/10.1001/jama. 2019.21565

8. McQueen RB, Geno Rasmussen C, Waugh K et al (2020) Cost and Cost-Effectiveness of Large-Scale Screening for Type 1 Diabetes in Colorado. Diabetes Care 43(7):1496-1503. https://doi.org/10. 2337/dc19-2003

9. Ziegler AG, Rewers M, Simell O et al (2013) Seroconversion to multiple islet autoantibodies and risk of progression to diabetes in children. JAMA 309(23):2473-2479. https://doi.org/10.1001/jama. 2013.6285

10. Bonifacio E, Mathieu C, Nepom GT et al (2017) Rebranding asymptomatic type 1 diabetes: the case for autoimmune beta cell disorder as a pathological and diagnostic entity. Diabetologia 60(1): 35-38. https://doi.org/10.1007/s00125-016-4144-8

11. Insel RA, Dunne JL, Atkinson MA et al (2015) Staging presymptomatic type 1 diabetes: a scientific statement of JDRF, the Endocrine Society, and the American Diabetes Association. Diabetes Care 38(10):1964-1974. https://doi.org/10.2337/dc151419

12. American Diabetes Association (2020) 2. Classification and Diagnosis of Diabetes: Standards of Medical Care in Diabetes2020. Diabetes Care 43(Suppl 1):S14-S31. https://doi.org/10. 2337/dc20-S002

13. Ismail HM, Cleves MA, Xu P et al (2020) The Pathological Evolution of Glucose Response Curves During the Progression to Type 1 Diabetes in the TrialNet Pathway to Prevention Study. Diabetes Care 43(11):2668-2674. https://doi.org/10.2337/dc200701

14. Decochez K, Truyen I, van der Auwera B et al (2005) Combined positivity for HLA DQ2/DQ8 and IA-2 antibodies defines population at high risk of developing type 1 diabetes. Diabetologia 48(4): 687-694. https://doi.org/10.1007/s00125-005-1702-x

15. Steck AK, Vehik K, Bonifacio E et al (2015) Predictors of Progression From the Appearance of Islet Autoantibodies to Early Childhood Diabetes: The Environmental Determinants of Diabetes in the Young (TEDDY). Diabetes Care 38(5):808-813. https://doi. org/10.2337/dc14-2426

16. Sosenko JM, Krischer JP, Palmer JP et al (2008) A risk score for type 1 diabetes derived from autoantibody-positive participants in the diabetes prevention trial-type 1. Diabetes Care 31(3):528-533. https://doi.org/10.2337/dc07-1459

17. Sosenko JM, Skyler JS, DiMeglio LA et al (2015) A new approach for diagnosing type 1 diabetes in autoantibody-positive individuals based on prediction and natural history. Diabetes Care 38(2):271276. https://doi.org/10.2337/dc14-1813

18. Simmons KM, Sosenko JM, Warnock M et al (2020) One-Hour Oral Glucose Tolerance Tests for the Prediction and Diagnostic Surveillance of Type 1 Diabetes. J Clin Endocrinol Metab 105(11):e4094-e4101

19. Insel RA, Dunne JL, Ziegler AG (2015) General population screening for type 1 diabetes: has its time come? Curr Opin Endocrinol Diabetes Obes 22(4):270-276. https://doi.org/10.1097/MED. 0000000000000173

20. Wentworth JM, Bediaga NG, Giles LC et al (2019) Beta cell function in type 1 diabetes determined from clinical and fasting biochemical variables. Diabetologia 62(1):33-40. https://doi.org/ 10.1007/s00125-018-4722-z

21. Diabetes Prevention Trial-Type 1 Diabetes Study Group (2002) Effects of insulin in relatives of patients with type 1 diabetes mellitus. N Engl J Med 346(22):1685-1691. https://doi.org/10. 1056/NEJMoa012350

22. Skyler JS, Krischer JP, Wolfsdorf J et al (2005) Effects of oral insulin in relatives of patients with type 1 diabetes: The Diabetes Prevention Trial-Type 1. Diabetes Care 28(5):1068-1076. https:// doi.org/10.2337/diacare.28.5.1068

23. Krischer JP, Lynch KF, Lernmark A et al (2017) Genetic and Environmental Interactions Modify the Risk of Diabetes-Related Autoimmunity by 6 Years of Age: The TEDDY Study. Diabetes Care 40(9):1194-1202. https://doi.org/10.2337/dc17-0238

24. Calcagno V, de Manancourt C (2010) glmulti: An R Package for Easy Automated Model Selection with (Generalized) Linear Models. J Stat Softw 34(12). https://doi.org/10.18637/jss.v034.i12

25. Therneau T (2020) A Package for Survival Analysis in R. R package version 3.1-12. Available from https://CRAN.R-project.org/ package $=$ survival. Accessed March 2020

26. Demler OV, Paynter NP, Cook NR (2015) Tests of calibration and goodness-of-fit in the survival setting. Stat Med 34(10):1659-1680. https://doi.org/10.1002/sim.6428

27. Robin X, Turck N, Hainard A et al (2011) pROC: an open-source package for $\mathrm{R}$ and $\mathrm{S}+$ to analyze and compare ROC curves. BMC Bioinformatics 12:77. https://doi.org/10.1186/1471-2105-12-77

28. Stene LC, Barriga K, Hoffman M et al (2006) Normal but increasing hemoglobin A1c levels predict progression from islet autoimmunity to overt type 1 diabetes: Diabetes Autoimmunity Study in the Young (DAISY). Pediatr Diabetes 7(5):247-253. https://doi. org/10.1111/j.1399-5448.2006.00198.x

29. Steck AK, Dong F, Frohnert BI et al (2018) Predicting progression to diabetes in islet autoantibody positive children. J Autoimmun 90: 59-63. https://doi.org/10.1016/j.jaut.2018.01.006

30. Jacobsen LM, Larsson HE, Tamura RN et al (2019) Predicting progression to type 1 diabetes from ages 3 to 6 in islet autoantibody positive TEDDY children. Pediatr Diabetes 20(3):263-270. https:// doi.org/10.1111/pedi.12812

31. Krischer JP, Liu X, Lernmark A et al (2017) The Influence of Type 1 Diabetes Genetic Susceptibility Regions, Age, Sex, and Family History on the Progression From Multiple Autoantibodies to Type 1 Diabetes: A TEDDY Study Report. Diabetes 66(12):3122-3129. https://doi.org/10.2337/db17-0261

32. Ismail HM, Xu P, Libman IM et al (2018) The shape of the glucose concentration curve during an oral glucose tolerance test predicts risk for type 1 diabetes. Diabetologia 61(1):84-92. https://doi.org/ 10.1007/s00125-017-4453-6

33. Fourlanos S, Varney MD, Tait BD et al (2008) The rising incidence of type 1 diabetes is accounted for by cases with lower-risk human leukocyte antigen genotypes. Diabetes Care 31(8):1546-1549. https://doi.org/10.2337/dc08-0239

34. Sosenko JM, Skyler JS, Mahon J et al (2011) Validation of the Diabetes Prevention Trial-Type 1 Risk Score in the TrialNet Natural History Study. Diabetes Care 34(8):1785-1787. https:// doi.org/10.2337/dc11-0641

35. Sosenko JM, Skyler JS, Mahon J et al (2014) Use of the Diabetes Prevention Trial-Type 1 Risk Score (DPTRS) for improving the accuracy of the risk classification of type 1 diabetes. Diabetes Care 37(4):979-984. https://doi.org/10.2337/dc13-2359

Publisher's note Springer Nature remains neutral with regard to jurisdictional claims in published maps and institutional affiliations. 